\title{
Mechanochemistry with Metallosupramolecular Polymers
}

\author{
Diederik W. R. Balkenende ${ }^{\ddagger}$, Souleymane Coulibaly ${ }^{\ddagger}$, Sandor Balog, Yoan C. Simon, Gina L. \\ Fiore and Christoph Weder* \\ Adolphe Merkle Institute, University of Fribourg, CH-170o, Fribourg, Switzerland. ${ }^{\ddagger}$ These authors contributed \\ equally. \\ CAS section: Chemistry of Synthetic High Polymers
}

\begin{abstract}
The transduction of mechanical force into useful chemical reactions is an emerging design approach to impart soft materials with new functions. Here, we report that mechanochemical transductions can be achieved in metallosupramolecular polymers. We show that both reversible and irreversible reactions are possible and useful to create mechanically responsive materials that display new functions. The metallopolymer studied was a crosslinked network assembled from a europium salt and a telechelic poly(ethylene-co-butylene) with 2,6-bis(1'-methylbenzimidazolyl)pyridine (Mebip) ligands at the termini. The $\mathrm{Eu}^{3+}$ complexes serve both as mechanically responsive binding motifs and built-in optical probes that can monitor the extent of (dis)assembly due to their characteristic photoluminescent properties. Indeed, dose-dependent and reversible metal-ligand dissociation occurs upon exposure to ultrasound in solution. The absence of ultrasound-induced dissociation of a low-molecular weight model complex and in-depth studies of temperature effects confirm that the dissociation is indeed the result of mechanical activation. The influence of the strength of the metal-ligand interactions on the mechanically induced dissociation was also explored. Metallopolymers in which the Mebip ligands were substituted with more strongly coordinating dipicolinate (dpa) ligands do not dissociate upon exposure to ultrasound. Finally we show that mechanochemical transduction in metallosupramolecular polymers is also possible in the solid state. We demonstrate mending of damaged objects through ultrasound as well as mechanochromic behavior based on metal-exchange reactions in metallopolymers imbibed with an auxiliary metal salt.
\end{abstract}

\section{Introduction}

Many mechanochemical transduction processes that translate macroscopic forces into chemical reactions and enable essential functions occur in Nature. This concept was recently mimicked in artificial polymers, ${ }^{2}$ which contain chemical motifs that dissociate upon mechanical activation and afford products that serve as catalysts, ${ }^{3}$ undergo color changes, ${ }^{4}$ or emit light. ${ }^{5}$ Several mechanochemically reactive moieties, referred to as "mechanophores", were shown to break when solutions of polymers containing these motifs were ultrasonicated ${ }^{6,7}$ and in some cases mechanochemically induced responses were demonstrated in solid materials. ${ }^{4,6 c, 8}$ Typical mechanophores utilized in this context are based on selective bond scission, extrusion of small molecules, cycloreversion, isomerization, and more recently on flex-activation. ${ }^{20,9}$ Interestingly, most synthetic mechanophores rely on the breaking of covalent bonds, which is very much in contrast to the mechanisms used by Nature. In order to enable a broad range of functions, such as cell motility, transport across ion-channels, or the formation of active enzymatic pockets, living organisms rely on mechanochemical transduction schemes that are based on a multitude of non-covalent interactions. ${ }^{1,10}$ Non-covalent interactions have also emerged as a useful design tool for stimuli-responsive functional polymers. ${ }^{11}$ Notable exam- ples include mechanochromic blends containing selfassembled excimer-forming dyes that can be dispersed upon mechanical deformation, ${ }^{12}$ healable polymers based on supramolecular motifs, which are presumed to dissociate upon application of excessive mechanical force, ${ }^{13}$ and the mechanochemically activated dissociation of coordination polymers, which are useful for mechanically activated catalysis. ${ }^{2 b, 2 d, 3,14}$ Here, we demonstrate that highly dynamic metallosupramolecular polymer networks based on weakly-coordinating metal-ligand complexes can also exhibit useful mechanochemical transduction. Both reversible and irreversible mechanically activated reactions are described, which were be used to impart these materials with useful functions, such as the ability of being healed by ultrasound and mechanochromic behavior.

\section{Results and Discussion}

The mechanically responsive metallosupramolecular polymer network studied is based on a previously reported ditopic macromonomer (number-average molecular weight, $\mathrm{M}_{\mathrm{n}},=4,400 \mathrm{~g} / \mathrm{mol}$ ) that was prepared by end-capping a lowmolecular-weight poly(ethylene-co-butylene) core with 2,6bis(1'-methylbenzimidazolyl)-pyridine (Mebip) ligands (BKB) (Figure 1a). ${ }^{15}$ 
a

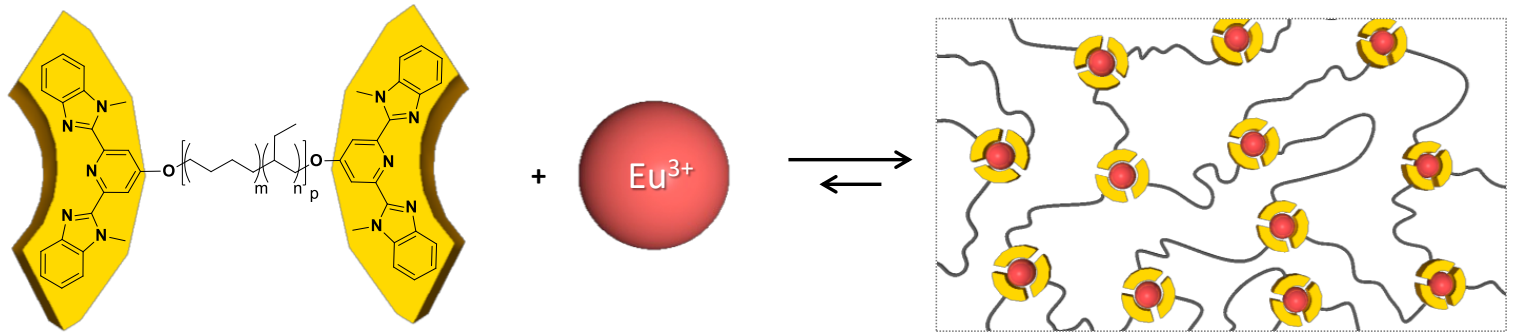

b
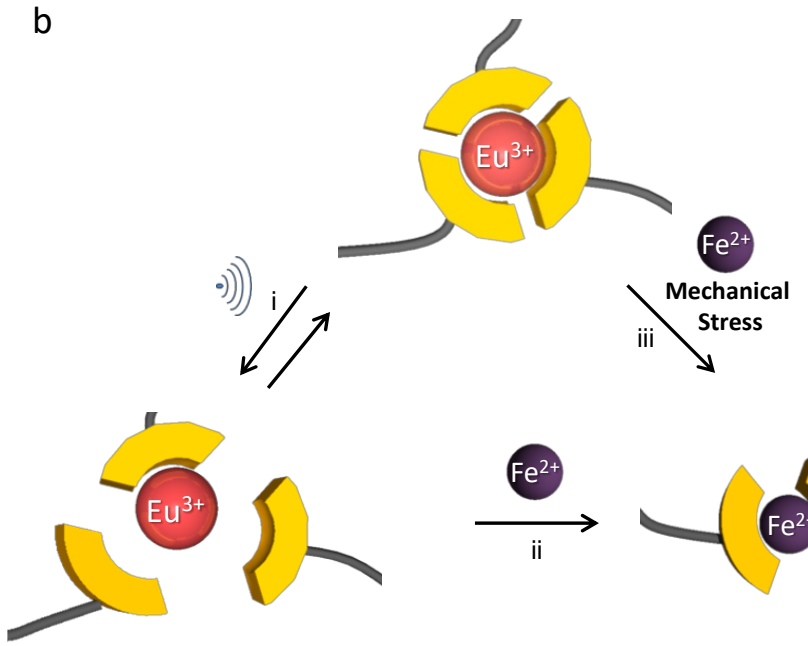



c



Figure 1. Chemical structure of the mechano-responsive metallosupramolecular polymer networks studied and schematic representation of (dis)assembly mechanisms. a, Formation of metallosupramolecular networks of the sum formula $\left[\mathrm{Eu}(\mathrm{BKB})_{1.5}\right]\left(\mathrm{ClO}_{4}\right)_{3}$ by combination of $\mathrm{BKB}$ and $\mathrm{Eu}\left(\mathrm{ClO}_{4}\right)_{3}$. The $\mathrm{ClO}_{4}{ }^{-}$counterions are omitted for clarity. b, (i) Reversible dissociation reaction of the $\mathrm{Eu}^{3+}$-ligand complexes in $\left[\mathrm{Eu}(\mathrm{BKB})_{1.5}\right]\left(\mathrm{ClO}_{4}\right)_{3}$ upon ultrasonication of these metallopolymers; irreversible metal exchange with $\mathrm{Fe}^{2+}$ ions in films of $\left[\mathrm{Eu}(\mathrm{BKB})_{1.5}\right]\left(\mathrm{ClO}_{4}\right)_{3}$ imbibed with a $\mathrm{Fe}\left(\mathrm{ClO}_{4}\right)_{2}$ solution as a result of (ii) ultrasonication or (iii) application of other mechanical forces. c, Deprotonated dipicolinic acid (dpa) ligands bind strongly to $\mathrm{Eu}^{3+}$ and these complexes can hardly be mechanically dissociated. The triethylammonium ions are omitted for clarity.

The multidentate Mebip ligand coordinates to transition metal ions, such as $\mathrm{Zn}^{2+}$, or lanthanide ions, such as $\mathrm{La}^{3+}$, to form dynamic bis-(transition metal ions) or tris(lanthanide ions) complexes, ${ }^{15-16}$ and the assembly of BKB with these cations affords linear or crosslinked (Figure a) metallosupramolecular polymers, respectively. ${ }^{16 a}$ Here, BKB was combined with europium perchlorate $\left(\mathrm{Eu}\left(\mathrm{ClO}_{4}\right)_{3}\right)$ to afford a metallosupramolecular network (Figure 1a) with the sum formula $\left[\mathrm{Eu}(\mathrm{BKB})_{1.5}\right]\left(\mathrm{ClO}_{4}\right)_{3}$. This design was motivated by the comparably weak and highly dynamic nature of $\mathrm{Eu}^{3^{+}}$-Mebip complexes, ${ }^{16 \mathrm{~d}, 16 \mathrm{e}}$ and the unique photoluminescence properties of $\mathrm{Eu}^{3+}$ ions, such as sharp emission lines and long excited state lifetimes. ${ }^{16 \mathrm{~d}, 17}$ Thus, the $\mathrm{Eu}^{3+}$-Mebip complex was expected to serve the dual role of a versatile supramolecular mechanophore (Figure $\mathrm{ib}$ ) and an internal optical probe that permits monitoring the extent of assembly. With the objective to study a reference material with a less dynamic binding motif, we also synthesized an analogue polymer (DKD). This macromonomer closely resembles BKB, but features dipicolinic acid (dpa) ligands at the termini, which in the deprotonated form bind much more strongly to $\mathrm{Eu}^{3+}$ than Mebip (Figure 1c). ${ }^{17-18}$
Thus, a dynamic $\left[\mathrm{Eu}(\mathrm{BKB})_{1.5}\right]\left(\mathrm{ClO}_{4}\right)_{3}$ network was prepared by combining 1.5 molar equivalents of $\mathrm{BKB}$ with one molar equivalent of $\mathrm{Eu}\left(\mathrm{ClO}_{4}\right)_{3}$ in a mixture of chloroform and acetonitrile. Similarly, a robust metallosupramolecular network with the sum formula $\left[\mathrm{Eu}(\mathrm{DKD})_{1.5}\right]\left(\mathrm{NHEt}_{3}\right)_{3}$ was prepared by deprotonation of the DKD macromonomer with triethylamine $\left(\mathrm{Et}_{3} \mathrm{~N}\right)$ and combination with europium chloride in chloroform and ethanol. In both cases, an instant viscosity increase indicated the formation of metallosupramolecular polymer networks. Evaporation of the solvents and subsequent compressionmolding resulted elastomeric films, which, unlike the neat macromonomers, displayed appreciable mechanical properties. Dynamic mechanical thermal analyses (DMTA) and tensile tests revealed a rubbery plateau between ca. -25 and $100{ }^{\circ} \mathrm{C}$, with room-temperature storage moduli of $23 \pm 6\left(\left[\mathrm{Eu}(\mathrm{BKB})_{1.5}\right]\left(\mathrm{ClO}_{4}\right)_{3}\right)$ and $8 \pm 2 \mathrm{MPa}$ ([Eu(DKD) $\left.\left.)_{1.5}\right]\left(\mathrm{NHEt}_{3}\right)_{3}\right)$ and maximum tensile strengths of $2 \pm 0.7 \quad\left(\left[\mathrm{Eu}(\mathrm{BKB})_{1.5}\right]\left(\mathrm{ClO}_{4}\right)_{3}\right)$ and $1.2 \quad \pm \quad 0.4 \mathrm{MPa}$ $\left(\left[\mathrm{Eu}(\mathrm{DKD})_{1.5}\right]\left(\mathrm{NHEt}_{3}\right)_{3}\right)$ (Table 1, Figures S1-S4). Differential scanning calorimetry traces (DSC, Figures $\mathrm{S}_{5}-\mathrm{S} 6$ ) reveal glass transition temperatures around $-51{ }^{\circ} \mathrm{C}$ and DMTA reveals a reduction of storage modulus around -30 ${ }^{\circ} \mathrm{C}$ for both $\left[\mathrm{Eu}(\mathrm{BKB})_{1.5}\right]\left(\mathrm{ClO}_{4}\right)_{3}$ and $\left[\mathrm{Eu}(\mathrm{DKD})_{1.5}\right]\left(\mathrm{NHEt}_{3}\right)_{3}$, which is also associated with the glass transition. Both 
DMTA and DSC analyses showed that the more labile $\left[\mathrm{Eu}(\mathrm{BKB})_{1.5}\right]\left(\mathrm{ClO}_{4}\right)_{3}$ network begins to dissociate above ca. $50{ }^{\circ} \mathrm{C}$, whereas $\left[\mathrm{Eu}(\mathrm{DKD})_{1.5}\right]\left(\mathrm{NHEt}_{3}\right)_{3}$ does not disassemble upon heating up to at least $115{ }^{\circ} \mathrm{C}$. Thermogravimetric analyses show a $2 \%$ weight loss at $181^{\circ} \mathrm{C}$ and $160^{\circ} \mathrm{C}$ for the two polymers and the trace of $\left[\mathrm{Eu}(\mathrm{BKB})_{1.5}\right]\left(\mathrm{ClO}_{4}\right)_{3}$ features a spontaneous decomposition loss around $275^{\circ} \mathrm{C}$, whereas $\left[\mathrm{Eu}(\mathrm{DKD})_{1.5}\right]\left(\mathrm{NHEt}_{3}\right)_{3}$ is stable up $>300{ }^{\circ} \mathrm{C}$ (Figures $\mathrm{S}_{7}-\mathrm{S} 8$ ). The lower stability of the $\left[\mathrm{Eu}(\mathrm{BKB})_{1.5}\right]\left(\mathrm{ClO}_{4}\right)_{3}$ is attributed to the degradation of the perchlorate counterion. ${ }^{16 c}$ Smallangle X-ray scattering (SAXS) data show multiple strong Bragg diffraction maxima for films of $\left[\mathrm{Eu}(\mathrm{BKB})_{1.5}\right]\left(\mathrm{ClO}_{4}\right)_{3}$, characteristic of a well-ordered layered morphology with a lamellar period of $7.3 \mathrm{~nm}$ (Figure S9). A similar morphology where the metal-ligand complexes form a "hard phase" that physically crosslinks "soft" domains formed by the poly(ethylene-co-butylene) cores was reported for polymers of $\mathrm{BKB}$ and $\mathrm{Zn}^{2+}$ or $\mathrm{La}^{3+} \cdot{ }^{16 a}$ Interestingly, the SAXS pattern of $\left[\mathrm{Eu}(\mathrm{DKD})_{1.5}\right]\left(\mathrm{NHEt}_{3}\right)_{3}$ (Figure Sio) reveals a disordered material with short-range order, indicated by shallow maxima around $\mathrm{q}=1 \mathrm{~nm}^{-1}$. This explains the lower stiffness and strength of the DKD-based polymer and indicates that stronger and less dynamic binding causes kinetic trapping of a largely disordered material.

In dilute $\mathrm{CHCl}_{3}$ solution, the free Mebip ligand in $\mathrm{BKB}$ displays an absorbance band with a maximum around 313 $\mathrm{nm}$ (Figure S11). The intensity of this transition decreases upon coordination with $\mathrm{Eu}\left(\mathrm{ClO}_{4}\right)_{3}$, and a broad shoulder around $365 \mathrm{~nm}$ develops, which can be assigned to the formation of a ligand-to-metal-charge-transfer (LMCT) transition. Concurrently, the photoluminescence spectrum changes from a broad peak associated with blue ligand emission with a maximum around $460 \mathrm{~nm}$ to a more intricate spectrum that features the characteristic sharp peaks associated with Eu-based ${ }^{5} \mathrm{D}_{0} \rightarrow{ }^{7} \mathrm{~F}_{J}$ transitions in the red regime of the spectrum (Figure 2a, Figure $\mathrm{S}_{12}$ ). The excitation spectrum of $\left[\mathrm{Eu}(\mathrm{BKB})_{1.5}\right]\left(\mathrm{ClO}_{4}\right)_{3}$ (Figure 2a) in which the emissive ${ }^{5} \mathrm{D}_{0} \rightarrow{ }^{7} \mathrm{~F}_{2}$ transition $\left(\lambda_{\max }=615 \mathrm{~nm}\right)$ is monitored, does not mirror the absorbance spectrum (Figure S12). Instead, a narrow peak centered around 375 $\mathrm{nm}$ can be observed, which reveals that the ${ }^{5} \mathrm{D}_{\mathrm{o}}$ level is most efficiently populated via the LMCT transition and not via excitation of the ligand. ${ }^{17}$ Excitation and emission spectra indicate that in dilute anhydrous $\mathrm{CHCl}_{3}$ solution $(2 \mathrm{mg} / \mathrm{mL})\left[\mathrm{Eu}(\mathrm{BKB})_{1.5}\right]\left(\mathrm{ClO}_{4}\right)_{3}$ is partially disassembled, as emission from both the free Mebip ligand and the $\mathrm{Eu}^{3+}$ Mebip complex can be observed (Figure 2a). Moreover, the minor splitting of the band associated with the ${ }^{5} \mathrm{D}_{0} \rightarrow{ }^{7} \mathrm{~F}_{2}$ transition, which is diagnostic of sample inhomogeneity, suggests that more than one emissive species is present. ${ }^{17}$

Mechanochemical transduction involving the new metallopolymer $\left[\mathrm{Eu}(\mathrm{BKB})_{1.5}\right]\left(\mathrm{ClO}_{4}\right)_{3}$ was first explored by ultrasonication of dilute solutions (Figure $\mathrm{rb}$, i). Indeed, upon ultrasonication, the photoluminescence color changed visibly from a saturated red and adapted a bluish hue (Figure 2b, Supporting Movie Mi). However, when the
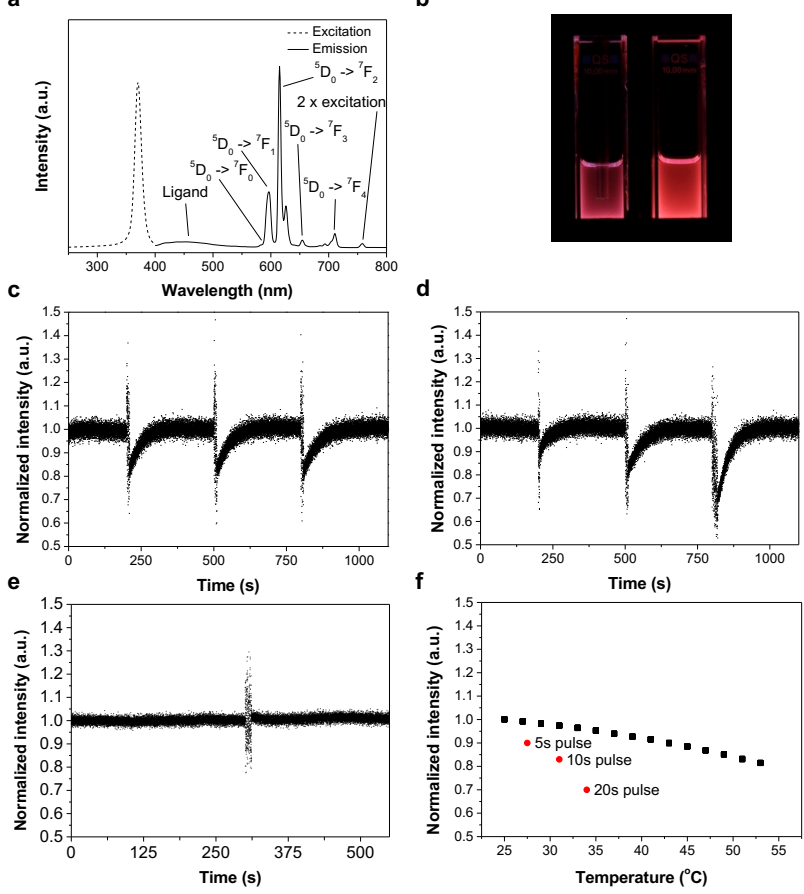

Figure 2. Monitoring the dynamics of the ultrasound triggered dissociation of metallosupramolecular polymers by photoluminescence spectroscopy. a, Excitation and emission spectra of a $\left[\mathrm{Eu}(\mathrm{BKB})_{1.5}\right]\left(\mathrm{ClO}_{4}\right)_{3}$ solution. Excitation and emission spectra were recorded with detection at $615 \mathrm{~nm}$ and excitation at $375 \mathrm{~nm}$, respectively. b, Picture (taken under illumination with $365 \mathrm{~nm}$ light) of cuvettes containing a solution of $\left[\mathrm{Eu}(\mathrm{BKB})_{1.5}\right]\left(\mathrm{ClO}_{4}\right)_{3}$ before (right) and after ultrasonication for $20 \mathrm{sec}$ (left). c, Normalized emission intensity of the $\mathrm{Eu}^{3+}:{ }^{5} \mathrm{D}_{\mathrm{o}} \rightarrow{ }^{7} \mathrm{~F}_{2}$ transition $(615 \mathrm{~nm}$, excitation at $375 \mathrm{~nm})$ for a solution of $\left[\mathrm{Eu}(\mathrm{BKB})_{1.5}\right]\left(\mathrm{ClO}_{4}\right)_{3}$ in $\mathrm{CHCl}_{3}$. The solution was subjected to three ultrasonication pulses of $10 \mathrm{sec}$. $d$, The experiment shown in (c) was repeated, but three ultrasonication pulses of 5,10 and 20 sec duration were applied. e, The experiment shown in (c) was repeated with a solution of $\left[\mathrm{Eu}\left(\mathrm{MebipC}_{12} \mathrm{H}_{25}\right)_{3}\right]\left(\mathrm{ClO}_{4}\right)_{3}$. f, Normalized emission intensity of the $\mathrm{Eu}^{3+}:{ }^{5} \mathrm{D}_{\mathrm{o}} \rightarrow{ }^{7} \mathrm{~F}_{2}$ transition $(615 \mathrm{~nm}$, excitation at $375 \mathrm{~nm})$ for a solution of $\left[\mathrm{Eu}(\mathrm{BKB})_{1.5}\right]\left(\mathrm{ClO}_{4}\right)_{3}$ of samples that were heated $(\bullet)$ or ultrasonicated $(\bullet$, data extracted from $(\mathbf{d}))$. All solutions were $2.0 \mathrm{mg} / \mathrm{mL}$ in $\mathrm{CHCl}_{3}$, except in (e) (o.30mM).

sonication was stopped, the original photoluminescence color was restored within a few minutes. The effect was quantitatively studied in situ by monitoring the intensity of the ${ }^{5} \mathrm{D}_{0} \rightarrow{ }^{7} \mathrm{~F}_{2}$ transition $\left(\lambda_{\max }=615 \mathrm{~nm}\right)$ of $\mathrm{a}$ $\left[\mathrm{Eu}(\mathrm{BKB})_{1.5}\right]\left(\mathrm{ClO}_{4}\right)_{3}$ solution using photoluminescence spectroscopy (Figure 2c,d, Figure $\mathrm{S}_{13}$ ). When the solution was subjected to an ultrasound pulse with a fixed duration of $10 \mathrm{sec}$ (Figure $2 \mathrm{c}$ ), the $\mathrm{Eu}^{3+}$-based emission decreased rapidly by about $20 \%$, which is consistent with the dissociation of the metallosupramolecular complex, and a reduction of the LMCT absorption (Supporting Discussion). The process was completely reversible; when the ultrasonication ceased the original intensity was restored, indicative of re-assembly of the metallosupramolecular polymer. The recovery dynamics appear to follow first order kinetics and can be fitted to a single exponen- 
tial (Figure S14). The recovery is much slower than might a priori be expected on the basis of the kinetic data of related complexes with small-molecule ligands, ${ }^{16 e}$ however, it is consistent with the formation of cross-linked networks and limited translational mobility of the telechelic ligands used here. Our data show that the reversible, ultrasound-induced dissociation of $\left[\mathrm{Eu}(\mathrm{BKB})_{1.5}\right]\left(\mathrm{ClO}_{4}\right)_{3}$ is reproducible if the duration of the sonication pulse is fixed (Figure 2c), and the level of dissociation increases with the length of the ultrasonication pulse applied (Figure $2 \mathrm{~d}$ ). A systematic study shows that the dissociation can be monitored via all ${ }^{5} \mathrm{D}_{0} \rightarrow{ }^{7} \mathrm{~F}_{J}$ transitions (Figure $\mathrm{S}_{15}$ ) and that a change of the concentration, at least in the range between $0.5-2 \mathrm{mg} / \mathrm{mL}$, does not affect the result (Figure S16). Gratifyingly, the low-molecular weight model complex $\left[\mathrm{Eu}\left(\mathrm{MebipC}_{12} \mathrm{H}_{25}\right)_{3}\right]\left(\mathrm{ClO}_{4}\right)_{3}$, formed in situ by the addition of three equivalents of monotopic Mebip $_{12} \mathrm{H}_{25}$ to a solution of anhydrous $\mathrm{Eu}\left(\mathrm{ClO}_{4}\right)_{3}$ in a mixture of $\mathrm{CHCl}_{3}$ and acetonitrile, did not show a decrease in the $\mathrm{Eu}^{3+}$ based emission upon ultrasonication (Figure 2e). As expected on the basis of many related experiments in the literature, the dodecane chains are too small to exert the ultrasound-induced mechanochemical force required for ligand dissociation (Figure 2e, Figure $\mathrm{S}_{17}$ ) and the experiments supports the conclusion that the ultrasound-induced dissociation of $\left[\mathrm{Eu}(\mathrm{BKB})_{1.5}\right]\left(\mathrm{ClO}_{4}\right)_{3}$ is indeed driven by mechanochemical transduction. ${ }^{2 e}$ We note that if this experiment was conducted after addition of water to the solution of anhydrous $\left[\mathrm{Eu}\left(\mathrm{MebipC}_{12} \mathrm{H}_{25}\right)_{3}\right]\left(\mathrm{ClO}_{4}\right)_{3}$, the dissociation and reassembly of ligands can be observed upon sonication. Since anhydrous lanthanide complexes are known to undergo hydrolysis, we speculate that this is due to ligand competition reactions (Figure $\mathrm{S} 18$ ). ${ }^{17}$

To explore to what extent thermal effects play a role in the dissociation of the metallosupramolecular materials studied here, the influence of temperature on the $\mathrm{Eu}^{3+}$ based emission was explored. Indeed, upon heating $\left[\mathrm{Eu}(\mathrm{BKB})_{1.5}\right]\left(\mathrm{ClO}_{4}\right)_{3}$ solutions, the intensity of the ${ }^{5} \mathrm{D}_{0} \rightarrow{ }^{7} \mathrm{~F}_{2}$ transition decreased, indicating that an increase in temperature can lead to depolymerization (Figure 2f). However, ultrasonication only causes a modest temperature increase of the solution. A comparison of the thermally and sonication-induced luminescence intensity changes reveals that in all ultrasonication experiments presented here the thermal contribution to the decrease in luminescence is marginal (Figure $2 \mathrm{f}$, Figure Sig). We note that also for $\left[\mathrm{Eu}\left(\mathrm{MebipC}_{12} \mathrm{H}_{25}\right)_{3}\right]\left(\mathrm{ClO}_{4}\right)_{3}$ a decrease in luminescence was only observed with increasing temperature, further supporting that ligand dissociation due to ultrasonication induced (local) thermal effects is minimal (Supporting Figure S2o). Reference experiments with the ultrasonication of $\mathrm{CHCl}_{3}$ revealed that the sonoluminescence ${ }^{19}$ of the solvent did not impact these experiments a solution of the neat BKB (that is, in the absence of metal salts) was not affected by exposure to ultrasound (Figures S21-S22). Photoluminescence spectroscopy was also used to probe the (dis)assembly of $\left[\mathrm{Eu}(\mathrm{DKD})_{1.5}\right]\left(\mathrm{NHEt}_{3}\right)_{3}$ in $\mathrm{CHCl}_{3}$ solution, for which much stronger metal-ligand co-
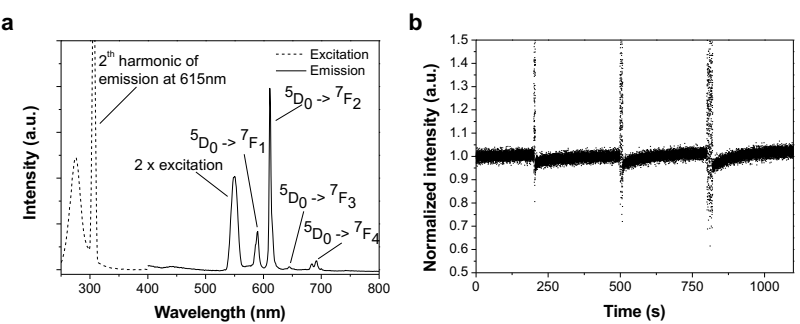

Figure 3. Monitoring the (dis)assembly of $\left[\mathrm{Eu}(\mathrm{DKD})_{1.5}\right]\left(\mathrm{NHEt}_{3}\right)_{3}$ by photoluminescence spectroscopy. a, Excitation and emission spectra of $\left[\mathrm{Eu}(\mathrm{DKD})_{1.5}\right]\left(\mathrm{NHEt}_{3}\right)_{3}$, recorded with detection at $615 \mathrm{~nm}$ and excitation at $275 \mathrm{~nm}$, respectively. $\mathbf{b}$, Normalized emission intensity of the $\mathrm{Eu}^{3^{+}}$: ${ }^{5} \mathrm{D}_{\mathrm{o}} \rightarrow{ }^{7} \mathrm{~F}_{2}$ transition $(615 \mathrm{~nm}$, excitation at $375 \mathrm{~nm})$ for a solution of $\left[\mathrm{Eu}(\mathrm{DKD})_{1.5}\right]\left(\mathrm{NHEt}_{3}\right)_{3}$. The solution was subjected to three ultrasonication pulses of 5,10 and $20 \mathrm{sec}$. a

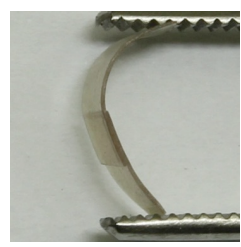

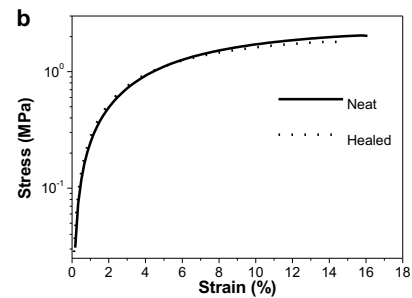

Figure 4. Welding by ultrasonication. a, Picture of a $\left[\mathrm{Eu}(\mathrm{BKB})_{1.5}\right]\left(\mathrm{ClO}_{4}\right)_{3}$ film that was cut and welded by exposure to ultrasonication in $\mathrm{CH}_{3} \mathrm{CN}$ as a transfer medium. b, Representative stress-strain curve of an original (solid line) and a cut and mended (dotted) film of $\left[\mathrm{Eu}(\mathrm{BKB})_{1.5}\right]\left(\mathrm{ClO}_{4}\right)_{3}$.

ordination was expected. ${ }^{18}$ The emission spectrum (Figure 3a) displays no splitting of the ${ }^{5} \mathrm{D}_{0} \rightarrow{ }^{7} \mathrm{~F}_{2}$ band, which supports the conclusion that even in dilute solution a highmolecular weight polymer was formed. The intensity of the ${ }^{5} \mathrm{D}_{0} \rightarrow{ }^{7} \mathrm{~F}_{2}$ band of this metallopolymer and of the corresponding model complex $\left[\mathrm{Eu}\left(\mathrm{dpaC}_{12} \mathrm{H}_{25}\right)_{3}\right]\left(\mathrm{NHEt}_{3}\right)_{3}$ did not change significantly upon ultrasonication (Figure $3 \mathrm{~b}$, Figures S23-S25), confirming a higher coordination strength for the dpa-based metallopolymer and highlighting that the mechano-responsive nature of these materials can indeed be tuned by changing the nature, that is strength and dynamics, of the metal-ligand complex.

Based on previous studies in which it was demonstrated that the stimuli-induced, reversible dissociation of supramolecular metallopolymers can be exploited to heal damages in these materials, ${ }^{16 a}$ we speculated that $\left[\mathrm{Eu}(\mathrm{BKB})_{1.5}\right]\left(\mathrm{ClO}_{4}\right)_{3}$ could be mechanically healable. Thus, films of this polymer were cut in half, lap-joints were formed, and the samples were gently pressed together and exposed to ultrasonication while either submersed in $\mathrm{CH}_{3} \mathrm{CN}$ or in a tightly sealed bag, shielded from the solvent. This process permits in both cases welding two pieces together (Figure 4a). Tensile tests and DMTA show that the original mechanical properties of the material were completely restored by this ultrasonic mending pro- 
Table 1. Mechanical properties of original and welded films of $\left[\mathrm{Eu}(\mathrm{BKB})_{1.5}\right]\left(\mathrm{ClO}_{4}\right)_{3}$.

\begin{tabular}{lcccccc}
\hline Samples & $\begin{array}{c}\text { Storage } \\
\text { Modulus } \\
(\mathrm{MPa})^{a}\end{array}$ & $\begin{array}{c}\text { Maximum } \\
\text { Stress } \\
(\mathrm{MPa})^{b}\end{array}$ & $\begin{array}{c}\text { Stress at } \\
\text { Break } \\
(\mathrm{MPa})^{b}\end{array}$ & $\begin{array}{c}\text { Stain at } \\
\text { Break } \\
(\%)^{b}\end{array}$ & $\begin{array}{c}\text { Young's } \\
\text { Modulus } \\
(\mathrm{MPa})^{b}\end{array}$ & $\begin{array}{c}\text { Toughness } \\
\left(\times 10^{4} \mathrm{~J} / \mathrm{m}^{3}\right)^{b}\end{array}$ \\
\hline Original $^{\mathrm{c}}$ & $23 \pm 6$ & $2.0 \pm 0.7$ & $1.6 \pm 0.2$ & $17 \pm 3$ & $24 \pm 5$ & $20 \pm 2$ \\
Cut and welded $^{\mathrm{d}}$ & $25 \pm 3$ & $2.1 \pm 0.9$ & $1.6 \pm 0.7$ & $14 \pm 4$ & $37 \pm 8$ & $20 \pm 6$
\end{tabular}

\begin{abstract}
${ }^{a}$ Measured by DMTA at $25{ }^{\circ} \mathrm{C} .{ }^{b}$ Measured by stress-strain experiments. ${ }^{c}$ Original indicates the original film after compression molding. ${ }^{d}$ Welded indicates dog bone samples mended after being cut, overlapped, and welded together. Data represent averages of $\mathrm{n}=5$ individual measurements \pm standard deviation. Toughness was calculated by integration of the area under the stress strain curves.
\end{abstract}

cess (Table 1, Figure 4b, Figure S26 and Table S1). No observable decrease of the luminescence emission intensity could be detected upon stretching of the samples, possibly due to the dynamic nature of the complexes and/or energy transfer processes. Interestingly, the mended samples did not break in the overlap areas; instead, failure occurred in the thinnest sections of the samples. In a reference experiment the mending experiment was repeated with a low-melting crystalline com-

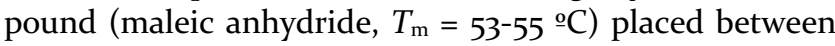
the overlapped area of the films, and no melting of the crystals was observed, indicating that ultrasonication did not cause the necessary temperature increase to trigger thermally-induced welding (Figure S27). Although sonochemical effects in the solid state are not unprecedented, ${ }^{20}$ the underlying mechanisms are much less understood than in solution. Reference experiments were conducted with films of $\left[\mathrm{Eu}(\mathrm{DKD})_{1.5}\right]\left(\mathrm{NHEt}_{3}\right)_{3}$ and also with the previously reported $[\mathrm{Zn}(\mathrm{BKB})]\left(\mathrm{NTf}_{2}\right)_{2},{ }^{16 \mathrm{a}}$ both featuring stronger metal-ligand binding motifs. In both cases, ultrasound welding was not possible, supporting the above-expressed conclusion that the nature of the supramolecular mechanophore strongly influences the responsiveness of the polymer.

We also discovered that it is possible to induce metalexchange reactions through mechanical activation (Figure $\mathrm{lb}$ ii and iii). Iron(II) (provided as perchlorate) was selected as auxiliary cation, because $\mathrm{Fe}^{2+}$-Mebip complexes are presumed to be strong and display a deep purple color on the account of a metal-to-ligand-charge-transfer transition. Therefore, an exchange of $\mathrm{Eu}^{3+}$ for $\mathrm{Fe}^{2+}$ should lead to a color change that can be readily detected with the unassisted eye. ${ }^{16 \mathrm{~b}}$ Thus, originally colorless films of $\left[\mathrm{Eu}(\mathrm{BKB})_{1.5}\right]\left(\mathrm{ClO}_{4}\right)_{3}$ (Figure 5a, Figure S28) were placed into an $\mathrm{Fe}\left(\mathrm{ClO}_{4}\right)_{2}$ solution in $\mathrm{CH}_{3} \mathrm{CN}$ until equilibrium swelling was established (Figure S29). While swelling was slow (equilibrium was reached only after 5 days), SAXS data and mechanical tests (Figures S9 and S3o) of samples that were swollen with the neat solvent and re-dried suggest that the solvent treatment per se did not significantly a

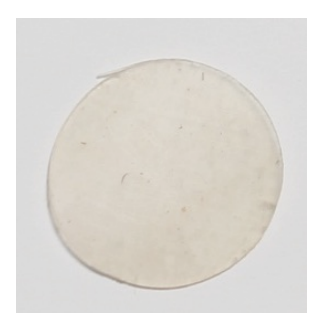

c

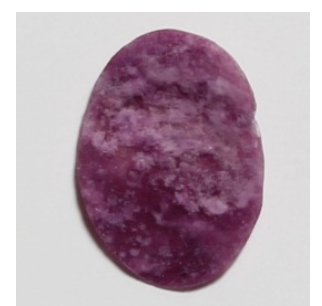

e

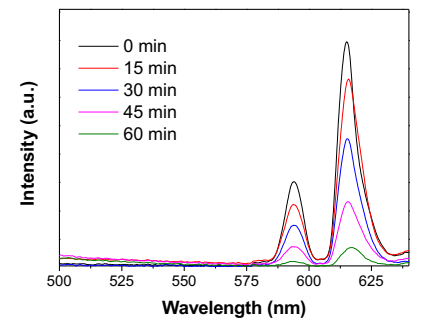

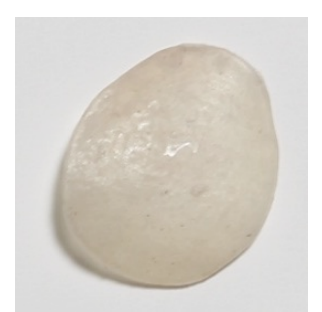

d

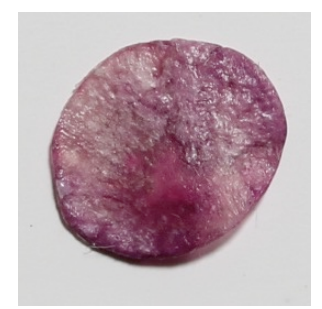

f

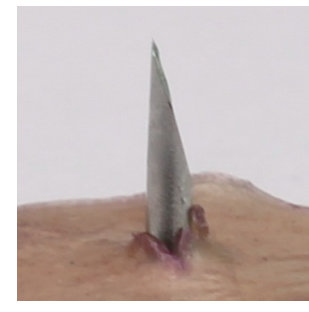

Figure 5. Mechanically induced metal exchange in $\left[\mathrm{Eu}(\mathrm{BKB})_{1.5}\right]\left(\mathrm{ClO}_{4}\right)_{3}$ films. Pictures of $\left[\mathrm{Eu}(\mathrm{BKB})_{1.5}\right]\left(\mathrm{ClO}_{4}\right)_{3}$ films before (a) and after (b) swelling in a solution of $\mathrm{Fe}\left(\mathrm{ClO}_{4}\right)_{2}$ in $\mathrm{CH}_{3} \mathrm{CN}(10 \mathrm{~mL}, 0.5 \mathrm{mM})$ for 5 days. c, Picture of a film treated as in (b) and subsequently ultrasonicated for $60 \mathrm{~min}(0.5 \mathrm{sec}$ pulse, 1 sec delay) in the $\mathrm{Fe}\left(\mathrm{ClO}_{4}\right)_{2}$ solution. d, Picture of a film treated as in (b) and subsequently ultrasonicated for 60 min (o.5 sec pulse, 1 sec delay, in neat $\mathrm{CH}_{3} \mathrm{CN}$. e, Emission spectra of a $\left[\mathrm{Eu}(\mathrm{BKB})_{1.5}\right]\left(\mathrm{ClO}_{4}\right)_{3}$ film as a function of ultrasonication time in $\mathrm{Fe}\left(\mathrm{ClO}_{4}\right)_{2}$ solution. The emission spectra were recorded using a fiber optic cable and excited at $365 \mathrm{~nm}$. f, Picture of a $\left[\mathrm{Eu}(\mathrm{BKB})_{1.5}\right]\left(\mathrm{ClO}_{4}\right)_{3}$ film(bottom) that was swollen in a $\mathrm{Fe}\left(\mathrm{ClO}_{4}\right)_{2}$ solution for $24 \mathrm{~h}$ and subsequently punctured with a needle. 
impact the morphology and mechanical properties of the samples. Rather surprisingly, as can be seen from Figure 5b, merely imbibing the metallopolymers with the $\mathrm{Fe}^{2+}$ salt did not cause an appreciable change of the visual appearance. However, when the imbibed films were ultrasonicated, either in the $\mathrm{Fe}^{2+}$ solution or in neat $\mathrm{CH}_{3} \mathrm{CN}$, the color changed gradually to the deep purple that is characteristic of the formation of the $\mathrm{Fe}^{2+}$-Mebip complex (Figures $1 \mathrm{~b}$ ii and $5 \mathrm{c}, \mathrm{d}$, Figure $\mathrm{S}_{31}$ ) and the $\mathrm{Eu}^{3+}$-based photoluminescence was switched off (Figure 5e). We note that the coloration was much less pronounced than in the case of independently made $[\mathrm{Fe}(\mathrm{BKB})]\left(\mathrm{ClO}_{4}\right)_{2}$ and conclude that the metal exchange is only partial. Accordingly, morphology and mechanical properties of $\left[\mathrm{Eu}(\mathrm{BKB})_{1.5}\right]\left(\mathrm{ClO}_{4}\right)_{3}$ films after metal exchange are largely unchanged, except for a minor increase of the lamellar period upon solvent treatment with or without the auxiliary salt (Table 1, Figures $\mathrm{S}_{9}, \mathrm{~S}_{32}-\mathrm{S}_{33}$, Table $\mathrm{S}_{1}$ ). Reference experiments were also performed with films of $\left[\mathrm{Eu}(\mathrm{DKD})_{1.5}\right]\left(\mathrm{NHEt}_{3}\right)_{3}$ and $[\mathrm{Zn}(\mathrm{BKB})]\left(\mathrm{NTf}_{2}\right)_{2}$, but in nei-

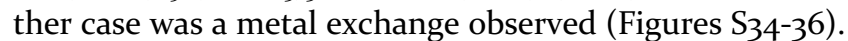
Remarkably, the metal-exchange could also be triggered through mechanical forces other than ultrasound. Thus, when $\mathrm{Fe}^{2+}$-imbibed, solvent-swollen films of $\left[\mathrm{Eu}(\mathrm{BKB})_{1.5}\right]\left(\mathrm{ClO}_{4}\right)_{3}$ were exposed to a mechanical force, such as gripping with tweezers or puncture by a needle (Figure $\mathrm{bb}$ iii and $5 \mathrm{f}$ ), an irreversible colorchange was observed. We note that mechanochromic polymers are useful, but still rare, ${ }^{2 \mathrm{~d}, 4,9 \mathrm{~b}}$ and this new approach to create such materials may therefore be of significant interest.

\section{Conclusions}

In conclusion, we have shown that the $\mathrm{Eu}^{3+}$-Mebip complex can serve as a mechanically responsive binding motif and a useful optical probe to quantify the metal complex disassembly process under mechanical strain. Metallosupramolecular polymer networks based on this mechanophore can undergo both reversible and irreversible mechanically induced reactions. The absence of ligand dissociation, that was observed for the thoroughly dried model compound, suggests that ultrasound-induced dissociation of the metallosupramolecular mechanophore is only possible in case of a high molecular weight metallosupramolecular polymer (network), as was also reported for covalent polymer mechanophores. Our work demonstrates that the mechano-responsiveness can be tailored by adjusting the supramolecular motif, which in the case of metallopolymers is readily achieved by the choice of the metal ion and the ligand. It appears that the general concept of mechanochemistry in supramolecular materials is versatile and can be extended to other types of weak interactions, that is, mechanophores that rely on hydrogen bonding, $\pi-\pi$ stacking, and other non-covalent bonds. This framework opens up avenues for the development of new materials capable of transducing (weak) forces into a useful outcome, including, as shown here, mechanically healable and mechanochromic materials.

\section{ASSOCIATED CONTENT}

Experimental methods, synthesic procedures, supporting discussion and additional characterization. This material is available free of charge via the Internet at http://pubs.acs.org.

\section{AUTHOR INFORMATION}

\section{Corresponding Author}

christoph.weder@unifr.ch

\section{Notes}

The authors declare no competing financial interests.

\section{ACKNOWLEDGMENT}

This material is based upon work supported by the U.S. Army Research Office (W911NF-09-1-0288 and W911NF-o6-10414), the Swiss National Science Foundation (Grant No. 200021_13540/1 and 51NF40_141849), the European Research Council (ERC-2011-AdG 291490-MERESPO), and the Adolphe Merkle Foundation. We thank Anita Roulin for her help with preliminary syntheses and technical support.

\section{REFERENCES}

(1) Heinrichs, A. Nat. Rev. Mol. Cell Bio. 2009, 10, 163.

(2) a. Brantley, J. N.; Wiggins, K. M.; Bielawski, C. W. Polym. Int. 2013, 62, 2; b. Wiggins, K. M.; Brantley, J. N.; Bielawski, C. W. ACS Macro Lett. 2012, 1, 623; c. Black, A. L.; Lenhardt, J. M.; Craig, S. L. J. Mater. Chem. 2011, 21, 1655; d. Weder, C. Nature 2009, 459, 45; e. Caruso, M. M.; Davis, D. A.; Shen, Q.; Odom, S. A.; Sottos, N. R.; White, S. R.; Moore, J. S. Chem. Rev. 2009, $109,5755$.

(3) Groote, R.; Jakobs, R. T. M.; Sijbesma, R. P. Polym. Chem. 2013, 4, 4846.

(4) Davis, D. A.; Hamilton, A.; Yang, J. L.; Cremar, L. D.; Van Gough, D.; Potisek, S. L.; Ong, M. T.; Braun, P. V.; Martinez, T. J.; White, S. R.; Moore, J. S.; Sottos, N. R. Nature 2009, 459, 68.

(5) Chen, Y.; Spiering, A. J. H.; Karthikeyan, S.; Peters, G. W. M.; Meijer, E. W.; Sijbesma, R. P. Nat. Chem. 2012, 4, 559 .

(6) a. Brantley, J. N.; Konda, S. S. M.; Makarov, D. E.; Bielawski, C. W. J. Am. Chem. Soc. 2012, 134, 9882; b. Wiggins, K. M.; Syrett, J. A.; Haddleton, D. M.; Bielawski, C. W. J. Am. Chem. Soc. 2011, 133, 7180; c. Lenhardt, J. M.; Black, A. L.; Craig, S. L. J. Am. Chem. Soc. 2009, 131, 10818; d. Beyer, M. K.; ClausenSchaumann, H. Chem. Rev. 2005, 105, 2921.

(7) Cravotto, G.; Cintas, P. Chem. Sci. 2012, 3, 295.

(8) a. Chen, Y. L.; Spiering, A. J. H.; Karthikeyan, S.; Peters, G. W. M.; Meijer, E. W.; Sijbesma, R. P. Nat. Chem. 2012, 4, 559; b. Lee, C. K.; Davis, D. A.; White, S. R.; Moore, J. S.; Sottos, N. R.; Braun, P. V. J. Am. Chem. Soc. 2010, 132, 16107.

(9) a. Larsen, M. B.; Boydston, A. J. J. Am. Chem. Soc. 2014, 136, 1276; b. Gossweiler, G. R.; Hewage, G. B.; Soriano, G.; Wang, Q.; Welshofer, G. W.; Zhao, X.; Craig, S. L. ACS Macro Lett. 2014, 3, 216.

(10) Gillespie, P. G.; Walker, R. G. Nature 2001, 413, 194.

(11) Wojtecki, R. J.; Meador, M. A.; Rowan, S. J. Nat. Mater. 2011, 10, 14 .

(12) a. Kunzelman, J.; Crenshaw, B. R.; Kinami, M.; Weder, C. Macromol. Rapid Commun. 2006, 27, 1981; b. 
Crenshaw, B. R.; Weder, C. Macromolecules 2006, 39, 9581; c. Lowe, C.; Weder, C. Adv. Mater. 2002, 14, 1625.

(13) a. Tennyson, A. G.; Wiggins, K. M.; Bielawski, C. W. J. Am. Chem. Soc. 2010, 132, 16631; b. Piermattei, A.; Karthikeyan, S.; Sijbesma, R. P. Nat. Chem. 2009, 1, 133; c. Cordier, P.; Tournilhac, F.; Soulie-Ziakovic, C.; Leibler, L. Nature 2008, 451, 977.

(14) a. Paulusse, J. M. J.; van Beek, D. J. M.; Sijbesma, R. P. J. Am. Chem. Soc. 2007, 129, 2392; b. Paulusse, J. M. J.; Sijbesma, R. P. Angew. Chem. Int. Ed. 2004, 43, 4460; c. Paulusse, J. M. J.; Huijbers, J. P. J.; Sijbesma, R. P. Chem. Eur. J. 2006, 12, 4928.

(15) Burnworth, M.; Mendez, J. D.; Schroeter, M.; Rowan, S. J.; Weder, C. Macromolecules 2008, 41, 2157.

(16) a. Burnworth, M.; Tang, L.; Kumpfer, J. R.; Duncan, A. J.; Beyer, F. L.; Fiore, G. L.; Rowan, S. J.; Weder, C. Nature 2011, 472, 334; b. Burnworth, M.; Knapton, D.;
Rowan, S. J.; Weder, C. J. Inorg. Organomet. Polm. 2007, 17, 91; c. Knapton, D.; Rowan, S. J.; Weder, C. Macromolecules 2006, 39, 651; d. Knapton, D.; Burnworth, M.; Rowan, S. J.; Weder, C. Angew. Chem. Int. Ed. 2006, 45, 5825; e. Escande, A.; Guénée, L.; Buchwalder, K.-L.; Piguet, C. Inorg. Chem. 2009, 48, 1132.

(17) Richardson, F. S. Chem. Rev. 1982, 82, 541.

(18) Vermonden, T.; de Vos, Wiebe M.; Marcelis, Antonius T. M.; Sudhölter, Ernst J. R. Eur. J. Inorg. Chem. 2004, 2004, 2847.

(19) Hilgenfeldt, S. Nat. Phys. 2006, 2, 435.

(20) Xu, H.; Zeiger, B. W.; Suslick, K. S. Chemical Society Reviews 2013, 42, 2555.

Table of Contents (TOC) graphic.

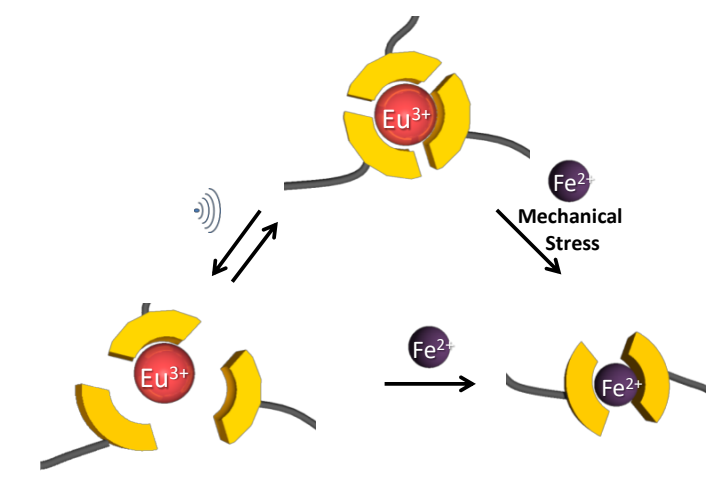

